\title{
The Hydrodynamic Moment of a Floating Structure in Finite Flowing Water
}

\author{
Zhen Cui ${ }^{1, *(D)}$, Shi-Yang $\operatorname{Pan}^{1}$ and Yue-Jun Chen ${ }^{2}[$ \\ 1 School of Civil and Architectural Engineering, Changzhou Institute of Technology, Changzhou 213032, China; \\ pansy@cit.edu.cn \\ 2 MWR Key Laboratory of Yellow River Sediment, Yellow River Institute of Hydraulic Research, Yellow River \\ Conservancy Comission, Zhengzhou 450003, China; chen-yuejun@hhu.edu.cn \\ * Correspondence: cuiz@cit.edu.cn; Tel.: +86-15996281130
}

check for updates

Citation: Cui, Z.; Pan, S.-Y.;

Chen, Y.-J. The Hydrodynamic

Moment of a Floating Structure in Finite Flowing Water. Fluids 2021, 6 , 307. https://doi.org/10.3390/ fluids 6090307

Academic Editors: Jaan H. Pu and Mehrdad Massoudi

Received: 24 June 2021

Accepted: 26 August 2021

Published: 31 August 2021

Publisher's Note: MDPI stays neutral with regard to jurisdictional claims in published maps and institutional affiliations.

Copyright: (C) 2021 by the authors Licensee MDPI, Basel, Switzerland. This article is an open access article distributed under the terms and conditions of the Creative Commons Attribution (CC BY) license (https:/ / creativecommons.org/licenses/by/ $4.0 /)$.

\begin{abstract}
The implementation of floating structures has increased with the construction of new sluices for flood control, and the hydrodynamic moment of a floating structure affects the safety and operation of that structure. Based on basic hydrodynamic theory, theoretical analysis and 121 physical model tests were conducted to study the relationships between the hydrodynamic moment and the influencing factors of floating structures, namely, the shape parameter, hydraulic conditions, and draft depth. Stepwise regression fitting based on the least squares method was performed to obtain a mathematical expression of the hydrodynamic moment, and the experimental results show that hydrodynamic factors significantly influence the hydrodynamic moment of such structures. The results predicted by the mathematical expression agree with the experimental results, and thus, the proposed expression can be used to comprehensively analyze and study the safety of a floating structure under the action of flow in finite water.
\end{abstract}

Keywords: floating structure; hydrodynamic moment; finite flowing water; physical model tests; statistical diagnosis

\section{Introduction}

There is an increasing trend in the applications of floating structures in inland water conservancy projects, such as inland navigation and flood control, as well as in marine engineering [1,2]. Such structures usually span a finite area (e.g., a river) with a large lengthto-width ratio and exhibit characteristics similar to those of ships, offshore platforms and sluices. However, the flow patterns of such structures are variable, and their hydrodynamic mechanisms are complex [3,4]. The hydrodynamic moment on the surface of a floating structure is generated by the action of the flow and can easily cause the structure to overturn. Consequently, studies on the stability of floating structures have focused primarily on the forces, influencing factors, and responses of such structures.

To investigate floating structures in infinite water, Lee and Hong [5] studied the wave force acting on a floating structure using physical experiments and verified a test of nonlinear waves acting on a structure via the marker and cell numerical method. It was found that installing a baffle on the structure can reduce the wave force and improve stability. Venugopal et al. [6] studied floating structures at different positions under wave action through physical model tests and found that different structure types (different depth-to-width ratios) influence the wave forces in the horizontal and vertical directions. Roy and Ghosh [7] measured the horizontal force and momentum of plates at different depths under wave action through model tests and found that the force and momentum converged with increasing wave periods and varied with the positions of the plates. Hayatdavoodi et al. [8] and Seiffert et al. [9] experimentally studied the force of solitary waves on coastal pontoons and discovered that the water depth, flow velocity, waves, and immersion depth of the pontoon affected the horizontal forces on the vessel. In addition, 
the vertical force decreased with increasing water level, and the experiments revealed that the interaction between waves and pontoon bridges could effectively change the force.

In contrast, the forces on and influencing factors of a floating structure in finite water are considerably different from those in infinite water. For instance, Xing et al. $[10,11]$ found that the response of a floating structure in finite water is different from that in infinite water; specifically, the boundaries of a finite domain act to reflect water waves, and a resonance phenomenon occurs between the operating structure and the water, with the additional mass-produced being related to the width of the water domain and time. Wang et al. [12,13] applied a numerical method to study the moments of floating structures in finite flowing water and found that the flow field and obtained moment varied differently with changes in the shape, position and water level conditions of the structure. Fu and Yin et al. [14] obtained the influencing factors of the speed of a floating sluice and the relationship between the overturning characteristics and ballast using hydraulic model tests. The results showed that the flow velocity of a sluice is related to the inflow (discharge) of water and that the safety of a floating sluice can be improved by increasing the ballast or reducing the water inflow. Lu and Wang [15] studied the hydraulic characteristics and corresponding velocity characteristics of a fixed floating structure under the action of solitary waves and reported that increasing the incident wave amplitude increases the vertical forces on the structure and that the horizontal force on the structure increases with increasing draft depth. Rodrigues and Guedes Soares [16] simulated the stability of floating structures with different shapes in still water and showed that the shape of the structure has a large influence on its stability. Cui et al. $[17,18]$ analyzed the influencing factors of the hydraulic characteristics around floating structures in finite flowing water and described the velocity distribution and the hydraulic characteristics, which were affected by the shape, position and hydraulic conditions of the structure. According to the principles of a system in equilibrium, Fu et al. [19] analyzed the hydraulic characteristics of a new type of floating sluice in a current based on hydraulic model tests and found that the stability of the structure was affected not only by its center-of-gravity position, free surface, ballast form and operating speed but also by the flow and constraint conditions.

Furthermore, Venugopal [20] experimentally studied the responses of regular and irregular floating structures under the actions of waves and currents and demonstrated that, unlike in static water, currents and the structure type affect the drag force and the inertia coefficient. Rey et al. [21] discussed floating structures under the simultaneous action of flow and waves and found that the water pressure and near-bottom velocity affect the bottoms of structures under deep water conditions and that the effects of waves and currents on the bottom of a submerged structure are not negligible. Johnson et al. [22] studied the stability of a floating breakwater under the action of waves and flow via physical tests and described the effects of the wave height and water flow velocity on the breakwater. On the basis of thin plate theory and linear potential flow, Wan et al. [23] verified the structural deformation and bending moment distribution of a floating structure via the modal function expansion method and the characteristic function expansion method. Zhang [24] systematically described the hydraulic characteristics of a floating gate operating under the action of water through experiments and numerical methods. Positive correlations were found between the rotational resistance and the draft depth, rotational speed, and flow velocity, and the pressure distribution on the water-facing surface of the gate was found to be greater than that on the downstream backwater surface. Rey and Touboul [25] studied the hydraulic load of a submerged plate under the action of water flow and discovered that the water flow influences both the reflection coefficient and the horizontal force acting on the plate but has little effect on the vertical force. Pu et al. [26,27] proposed a method to improve the measured velocity and turbulence structure data in the near-bed region through experimental and computational approaches. Li and Lin [28] developed a two-dimensional numerical calculation method under wave and current conditions and discussed the hydrodynamic coefficients corresponding to a cylindrical floating structure 
affected by waves and currents. The drag force was found to decrease as the wave height increased, while the inertial force decreased only slightly.

The purpose of this paper is to analyze the hydrodynamic moment characteristics of a floating structure in finite flowing water. The hydrodynamic pressure on a floating structure influences whether the structure overturns; this phenomenon motivates the development of a method to accurately calculate the overturning moment via the hydrodynamic pressure. Based on dimensional analysis, the influencing factors of the floating hydrodynamic moment are studied by conducting a large number of physical experiments with respect to the shape, flow parameters, and draft depth of the floating structure, and the variations in and characteristics of the hydrodynamic moment are obtained. In light of the experimental results, a formula of the overturning moment in terms of the hydrodynamic pressure in flowing water is given. Moreover, the statistical theory is applied to diagnose and verify the correctness of the formula to provide a basis for the safe operational control of a floating structure under the action of flow, which has important theoretical significance and practical application value.

\section{Experimental Design and Configuration}

When a floating structure is employed in a water conservancy project, it is used to control the water level and regulate the flow. A floating structure operates either in a submerged state (completely immersed in the water) or a floating state (partially submerged in the water). The influencing factors that affect the hydrodynamic moment and measurement methods of floating structures in these submerged and floating states are not the same. Hence, the hydrodynamic moment of a floating structure in a submerged state has previously been qualitatively and quantitatively analyzed by arranging miniature dynamic pressure sensors on the surface of the structure through the microintegral method [29]. However, because part of a floating structure in a floating state remains above the water surface, which is inherently different from the submerged state, the hydrodynamic moments of floating structures in a floating state should also be studied.

\subsection{Experimental Configuration and Dynamic Moment Measurement}

During the operation of a floating structure in flowing water, the factors affecting the hydrodynamic moment mainly include the shape of the floating structure, the draft depth of the structure, and the hydraulic conditions. According to the factors affecting the hydrodynamic moment in hydraulic engineering, indoor experiments were established, and the main parameter conditions were analyzed. Flume experiments involving a selfcirculating water supply system were performed to study the hydraulic characteristics and patterns of the hydrodynamic moment of a floating structure; the flume was made of plexiglass with a smooth surface. The moment and hydraulic parameters were measured under steady flow conditions. The experimental configuration is presented in Figure 1a; as shown in Figure 1b, the floating structure was set in the central area of the flume. With the width of the floating structure perpendicular to the flume being $0.30 \mathrm{~m}$, water flowed downstream beneath the structure rather than around it. An independently developed stepper motor and computerized numerical control (CNC) speed control system was used to control the position of the floating structure at an accuracy of $0.10 \mathrm{~mm}$. The upstream and downstream water levels of the model were measured using needle water level gauges with a measurement accuracy of $\pm 0.10 \mathrm{~mm}$. Typical velocities were obtained by an acoustic Doppler velocimeter at an accuracy of $0.01 \mathrm{~cm} / \mathrm{s}$, and the acquisition frequency was $200 \mathrm{~Hz}[30,31]$. The flow characteristics around the floating structure were observed along the longitudinal section. 


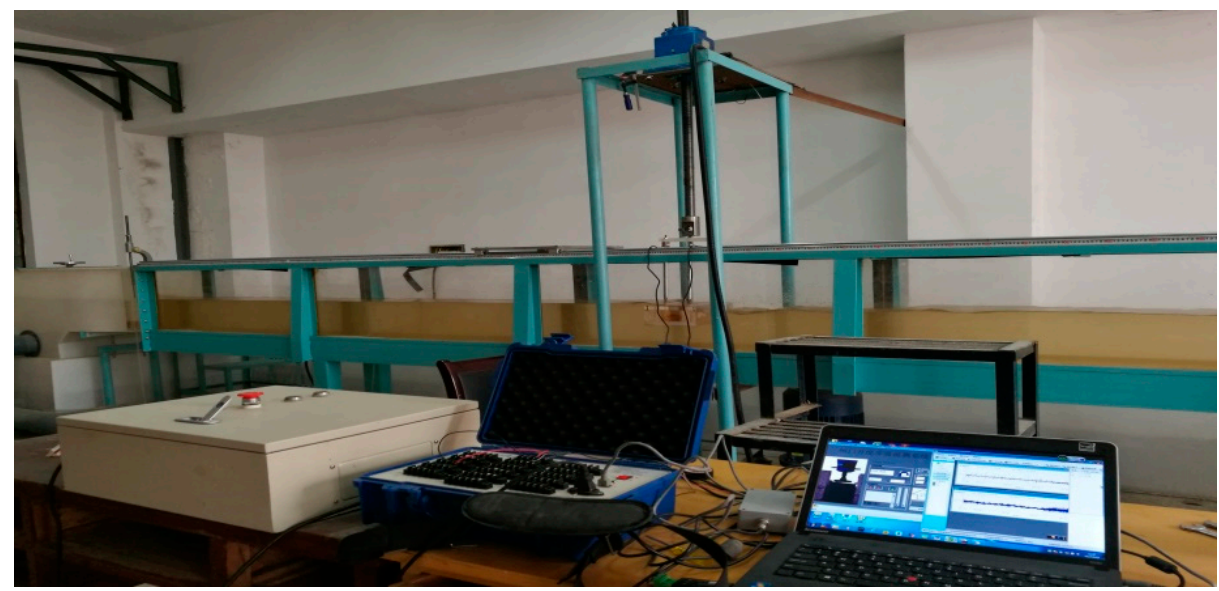

(a)

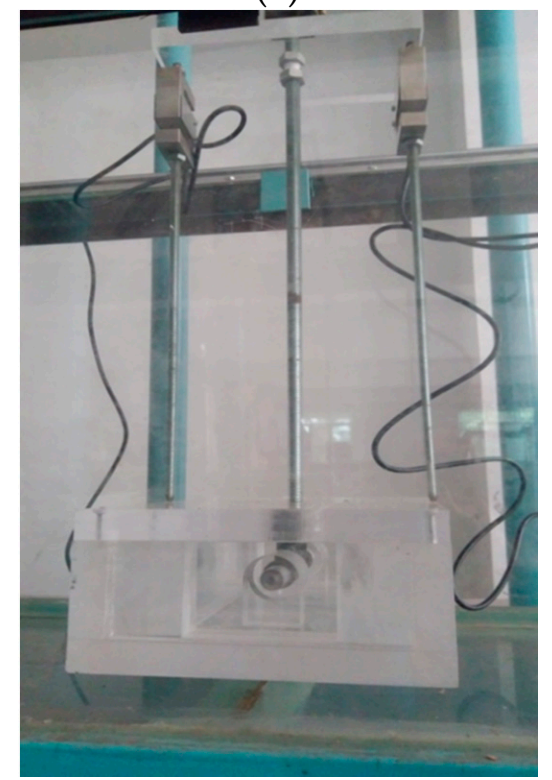

(b)

Figure 1. Diagram of the test model: (a) Panoramic view of the experimental configuration, (b) The diagram of the floating structure.

To measure the hydrodynamic moment of the structure, the fixed floating structure capable of both sinking and floating was connected to a rotating rod set at the geometric center of the structure to ensure that the structure could freely (but only slightly) rotate along the direction of the water flow, and a tension pressure sensor was arranged along the center line of water flow at each end (upstream and downstream) of the upper part of the structure. The sensor was a CY201 digital pressure and temperature transmitter with an accuracy of $\pm 0.50 \%$, and the acquisition frequency was $512 \mathrm{~Hz}$. When a floating structure is under the action of flow, it rotates along the direction of the flow; therefore, the hydrodynamic moment can be calculated by the pressure values output from the tension pressure sensors (see Figure 2). The pressures on the two sensors are denoted $F_{1}$ and $F_{2}$, and the distances from the center of the structure to the sensors are denoted $D_{1}$ and $D_{2}$, respectively. The hydrodynamic moment was calculated with clockwise being negative and counterclockwise being positive as follows:

$$
M=F_{1} D_{1}-F_{2} D_{2}
$$




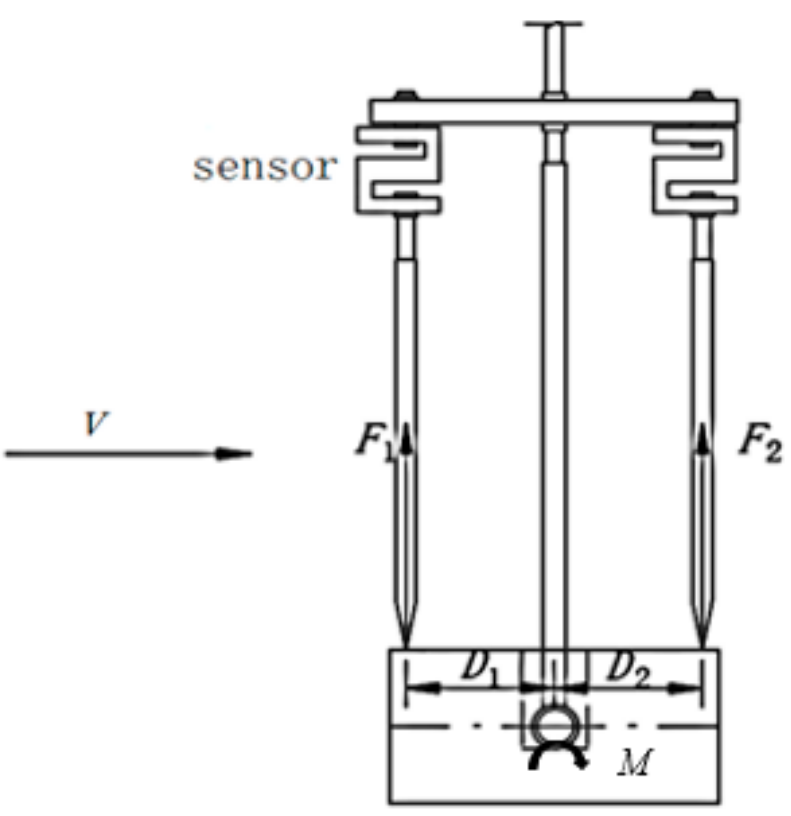

(a)

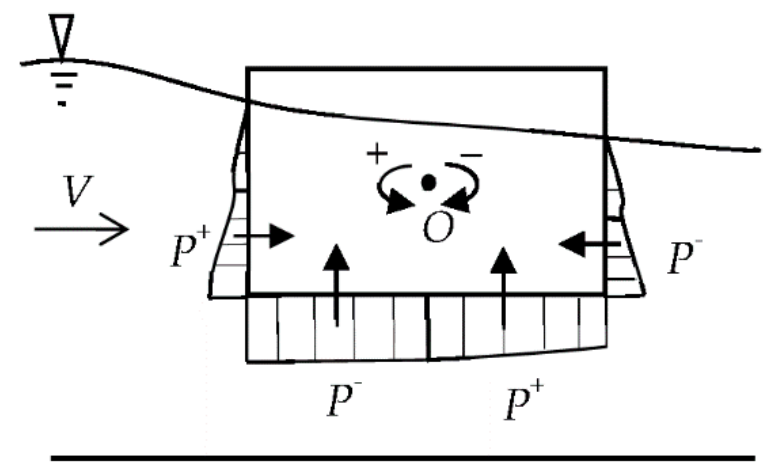

(b)

Figure 2. Schematic of moment measurement: (a) Layout of the sensor, (b) Pressure profile of the floating structure.

\subsection{Dimensional Analysis and Parameter Design of the Floating Structure}

The flow pattern around a floating structure is complicated, and the surrounding velocity distribution is uneven, which affects the dynamic moment and stability when the structure moves upward and downward during operation.

We define the hydrodynamic moment of a floating structure per unit length ( $L=1.00 \mathrm{~m})$ as $M_{\text {Floating }}$ or $M_{F}$ for short. The influencing factors of $M_{F}\left[\mathrm{MLT}^{-2}\right.$ ] mainly include the width of the structure $B([\mathrm{~L}])$, the height of the structure $a$ ([L]), a draft of the structure $h([\mathrm{~L}])$, downstream water depth $H^{\prime}$ ([L]), gravitational constant of acceleration $g\left(\left[\mathrm{LT}^{-2}\right]\right)$, water density $\rho\left(\left[\mathrm{ML}^{-3}\right]\right)$, upstream and downstream water level difference $\Delta H([\mathrm{~L}])$, and average velocity of the upstream section $v\left(\left[\mathrm{LT}^{-1}\right]\right)$. Figure 3 shows a schematic diagram of the main parameters affecting the floating structure. According to dimensional analysis, the expression of the parameters influencing the hydrodynamic moment is as follows:

$$
\mathrm{f}\left(M_{F}, B, g, \rho, a, h, \Delta H, H^{\prime}, v\right)=0
$$


Floating structure

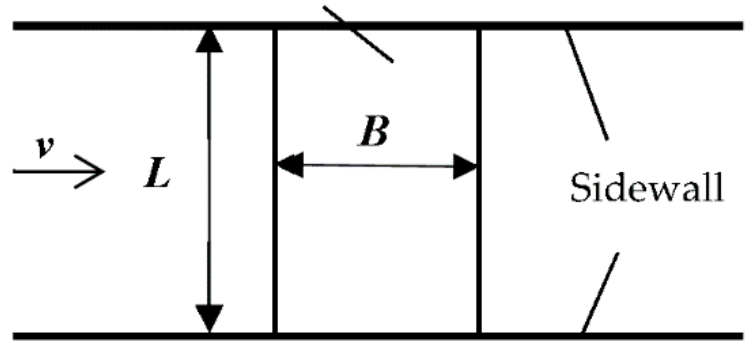

(a)

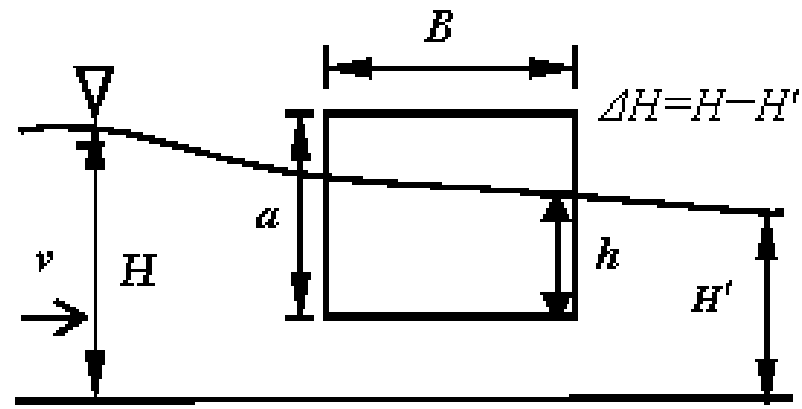

(b)

Figure 3. Main parameters of the floating structure: (a) Plan view, (b) Front view.

The downstream water depth $H^{\prime}([\mathrm{L}])$ in the geometric dimension, gravitational constant of acceleration $g\left[\mathrm{~L} / \mathrm{T}^{2}\right]$ in the kinematic dimension, and water density $\rho$ in the dynamic dimension $\left(\left[\mathrm{ML}^{-3}\right]\right)$ are selected as the three basic physical quantities. According to the $\pi$ theorem:

$$
\frac{M_{F}}{\rho g H^{\prime 3}}=f\left(\frac{B}{H^{\prime}}, \frac{a}{H^{\prime}}, \frac{h}{H^{\prime}}, \frac{\Delta H}{H^{\prime}}, \text { Fr }\right)
$$

where the dimensionless factor on the left side is defined as $M_{f}$. We define $\pi_{2} / \pi_{3}=B / a$ as the aspect ratio of the floating structure; $h / H^{\prime}$ is the relative draft; $\Delta H / H^{\prime}$ is the relative water level difference, and $\pi_{6}=\mathrm{Fr}=v / \sqrt{g H}$ is the Froude number of the upstream section. The length of the section is five times the water depth of the flume at the upstream end of the floating structure, where the flow is stable and is not affected by the structure. The simplified result is:

$$
M_{f}=f\left(\frac{B}{a}, \frac{h}{H^{\prime}}, \frac{\Delta H}{H^{\prime}}, \mathrm{Fr}\right)
$$

The dimensionless hydrodynamic moment of the floating structure is related to the shape $B / a$, the relative draft $h / H^{\prime}$, the relative water level difference $\Delta H / H^{\prime}$ of the floating structure, and the Froude number Fr.

The influencing factors of the hydrodynamic moment are the shape of the floating structure, upstream and downstream water levels, draft depth, and inflow conditions. The height of the floating structure $a$ selected in the experiment was $10.00 \mathrm{~cm}$. Four different widths of floating structure $B$ were selected $(10.00 \mathrm{~cm}, 20.00 \mathrm{~cm}, 30.00 \mathrm{~cm}$, and $40.00 \mathrm{~cm})$; therefore, the width-to-height aspect ratios were 1.00, 2.00, 3.00, and 4.00, respectively. The flow rates per unit width were set to $0.05 \mathrm{~m}^{2} / \mathrm{s}, 0.06 \mathrm{~m}^{2} / \mathrm{s}, 0.07 \mathrm{~m}^{2} / \mathrm{s}$, and $0.08 \mathrm{~m}^{2} / \mathrm{s}$; the draft depths of the structure were $2.00 \mathrm{~cm}, 4.00 \mathrm{~cm}, 6.00 \mathrm{~cm}$, and $8.00 \mathrm{~cm}$; and the downstream water levels were $18.00 \mathrm{~cm}, 20.00 \mathrm{~cm}, 22.00 \mathrm{~cm}$, and $24.00 \mathrm{~cm}$, respectively (see in Table 1). To ensure the completeness of the test, orthogonal tests were also conducted, resulting in a total of 121 test groups. 
Table 1. Experimental parameters.

\begin{tabular}{|c|c|c|c|c|c|c|c|}
\hline$a / \mathrm{m}$ & $B / \mathrm{m}$ & $h / m$ & $q /\left(\mathrm{m}^{2} \mathrm{~s}^{-1}\right)$ & & & & \\
\hline \multirow{16}{*}{0.10} & \multirow{16}{*}{$\begin{array}{l}0.10 \\
0.20 \\
0.30 \\
0.40\end{array}$} & \multirow{4}{*}{0.02} & 0.05 & 0.18 & 0.20 & 0.22 & 0.24 \\
\hline & & & 0.06 & 0.18 & 0.20 & 0.22 & 0.24 \\
\hline & & & 0.07 & 0.18 & 0.20 & 0.22 & 0.24 \\
\hline & & & 0.08 & 0.18 & 0.20 & 0.22 & 0.24 \\
\hline & & \multirow{4}{*}{0.04} & 0.05 & 0.18 & 0.20 & 0.22 & 0.24 \\
\hline & & & 0.06 & 0.18 & 0.20 & 0.22 & 0.24 \\
\hline & & & 0.07 & 0.18 & 0.20 & 0.22 & 0.24 \\
\hline & & & 0.08 & 0.18 & 0.20 & 0.22 & 0.24 \\
\hline & & \multirow{4}{*}{0.06} & 0.05 & 0.18 & 0.20 & 0.22 & 0.24 \\
\hline & & & 0.06 & 0.18 & 0.20 & 0.22 & 0.24 \\
\hline & & & 0.07 & 0.18 & 0.20 & 0.22 & 0.24 \\
\hline & & & 0.08 & 0.18 & 0.20 & 0.22 & 0.24 \\
\hline & & \multirow{4}{*}{0.08} & 0.05 & 0.18 & 0.20 & 0.22 & 0.24 \\
\hline & & & 0.06 & 0.18 & 0.20 & 0.22 & 0.24 \\
\hline & & & 0.07 & 0.18 & 0.20 & 0.22 & 0.24 \\
\hline & & & 0.08 & 0.18 & 0.20 & 0.22 & 0.24 \\
\hline
\end{tabular}

\section{Results and Discussion}

Figure 4 shows a schematic diagram of the flow along the longitudinal section. Due to the existence of the floating structure, the flow from the upstream region passes under the structure, which reduces the cross-section of the water flow and increases the velocity; on the front surface of the structure, the velocity is parallel to the flow direction is zero. The water surface profile drops slightly in the upstream region of the structure, and the water level on the front surface of the floating body is higher than that on the back surface. The presence of the structure creates a recirculation zone in the downstream region, which causes the pressure on the back surface of the structure to decrease.

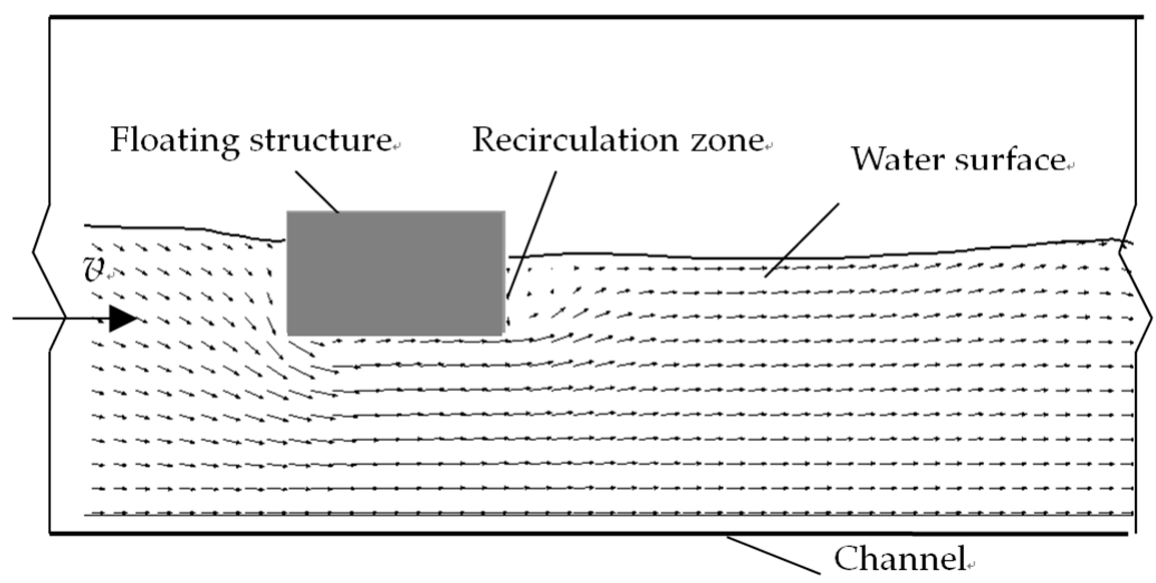

Figure 4. Schematic diagram of the flow.

\subsection{Shape of the Floating Structure}

Figure 5 shows a scatter diagram relating the dimensionless hydrodynamic moment $M_{f}$ to the structure shape parameter B/a under the same hydraulic conditions. With increasing $B / a, M_{f}$ increases. During the experiment, with increasing $B / a$, the flow velocity decreases significantly near the center of the structure's lower surface. The small recirculation zone near the lower center of the structure expands to the back half of the structure. When the shape parameter of the floating structure increases, the surface pressure difference caused by the uneven distribution of the dynamic pressure increases, and the distance between the action point and the center of the structure also increases, resulting in a rise in the hydrodynamic moment. For a larger structure, the pressure drop from the entrance of 
the bottom gap to the downstream part increases, causing an increased pressure difference and giving rise to the hydrodynamic moment.

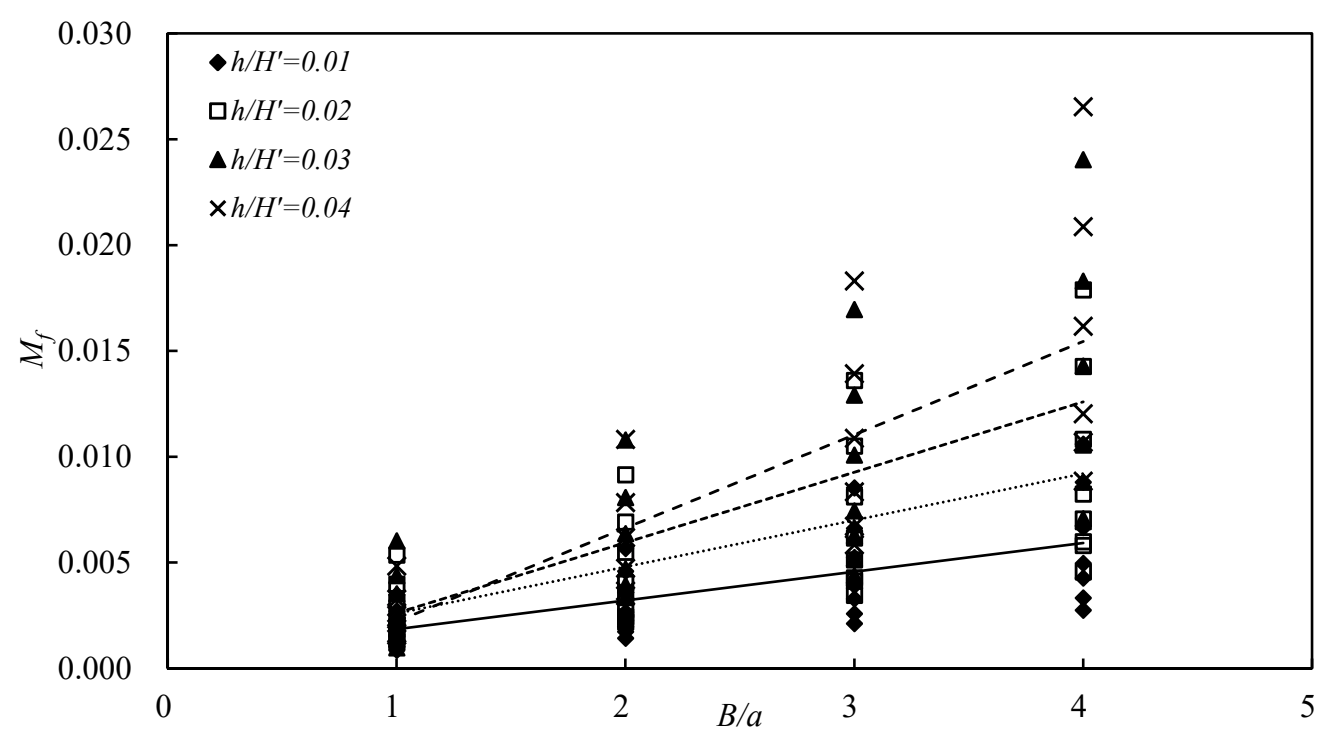

Figure 5. Relationship between $M_{f}$ and the floating structure's shape.

The slope in the graph increases with increasing $h / H^{\prime}$ and shows a linear relationship. The relationship between the shape of the structure and $M_{f}$ was obtained through a fitting analysis:

$$
M_{f}=k_{1} B h / a H^{\prime}+c_{1}
$$

where $k_{1}$ and $c_{1}$ are the coefficient and constant terms, respectively, of the independent variable $B h / a H^{\prime}$.

\subsection{Draft Depth}

When the downstream water depth changes, the relationship between the relative draft depth and the hydrodynamic moment is complicated. However, when the factors $h / H^{\prime}$ and $\Delta H / H^{\prime}$ are combined, an obvious pattern emerges. Figure 6 shows the relationship between $M_{f}$ and $h / \Delta H$, indicating that $M_{f}$ has an obvious logarithmic relationship with $h / \Delta H$, and its value increases with increasing $B / a$. A non-uniform distribution of the flow velocity causes a change in the hydrodynamic moment at different draft depths. The hydrodynamic pressure acting on the surface of the structure decreases obviously if the draft depth is small. When the water level difference increases, the velocity around the floating structure rises, and the pressure difference between the front and back surfaces of the structure increases, resulting in an increase in the hydrodynamic moment.

In addition, there is a negative linear correlation between $B / a$ and the coefficient term $k_{2}$. Hence, the correlation between $M_{f}$ and the draft depth can be expressed as follows:

$$
M_{f}=k_{2} \frac{B}{a} \ln \left(\frac{h}{\Delta H}\right)+c_{2}
$$

where $k_{2}$ and $c_{2}$ are the coefficient and constant terms, respectively, of the independent variable $\ln \left(\frac{h}{\Delta H}\right)$. 


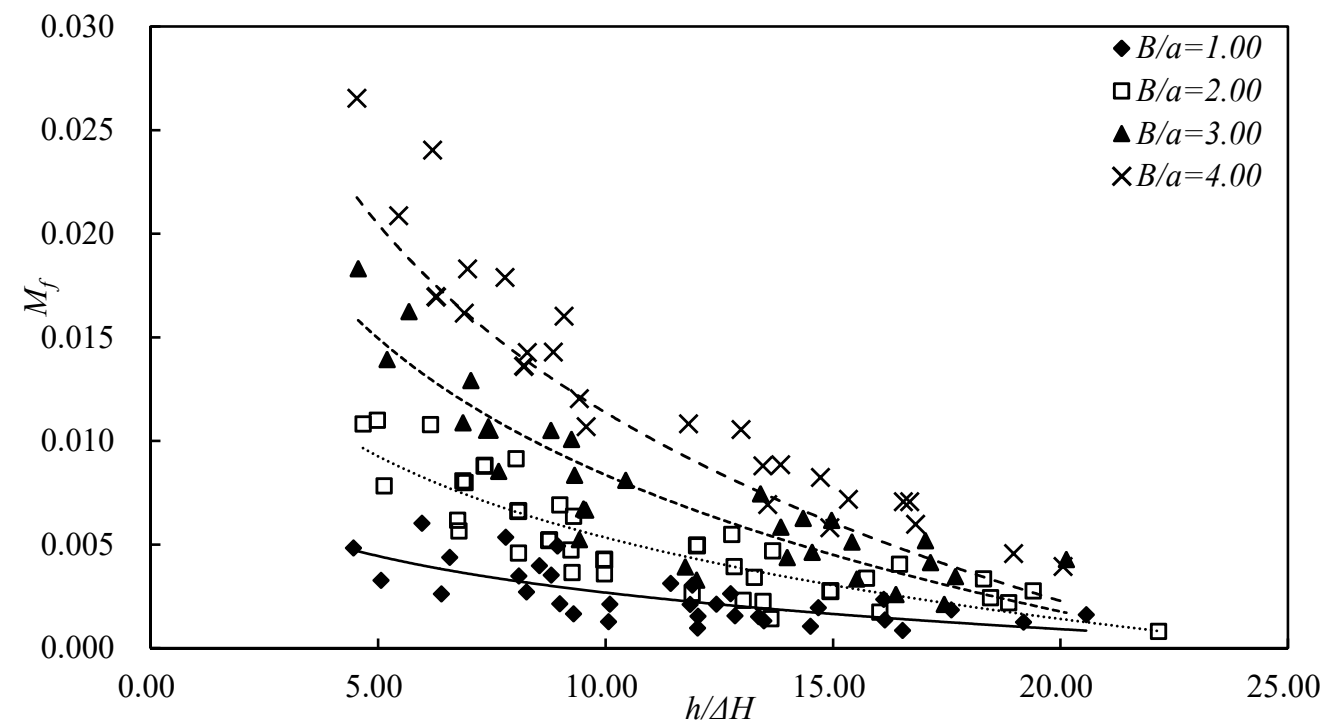

Figure 6. Relationship between $M_{f}$ and the draft depth.

\subsection{Relative Water Level Difference}

Figure 7 shows the relationship between $M_{f}$ and the relative water level difference $\Delta H / H^{\prime} . M_{f}$ increases with increasing $\Delta H / H^{\prime}$, and when the structure is large, the growth rate of the hydrodynamic moment shows an increasing trend. This is similar to the conclusion that the moment increases with increasing $B / a$. When $\Delta H / H^{\prime}$ increases, the pressure difference between the front and back surfaces of the structure increases. With an increasing water level difference, the hydrodynamic pressure acting on the upstream face of the floating structure is obviously higher than that acting on the downstream face; therefore, the structure tilts downstream, and the moment increases obviously. The hydrodynamic pressure acting on the downstream face was found to be relatively low due to the recirculation zone existing near the downstream face of the structure. As a consequence, the structure becomes increasingly unstable as a result of the increasing water level difference and thus can be easily unbalanced.

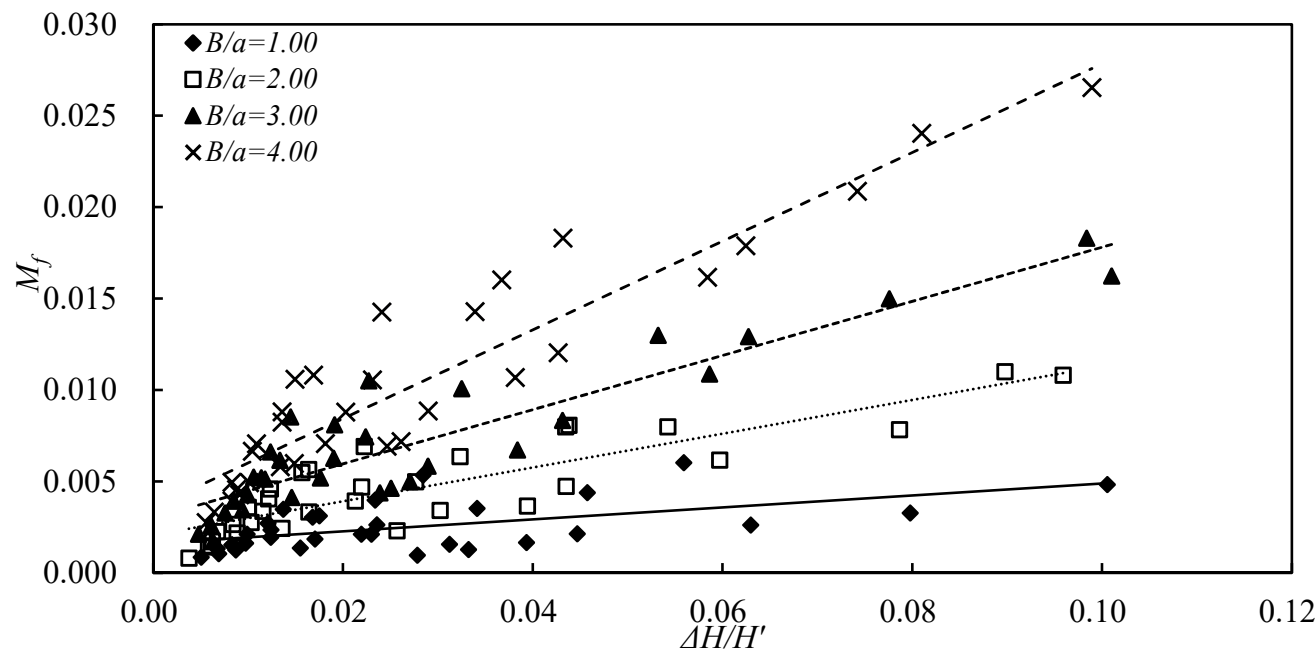

Figure 7. Relationship between $M_{f}$ and $\Delta H / H^{\prime}$.

There is a clear linear relationship between the different slopes and $B / a$. The relationship between $M_{f}$ and $\Delta H / H^{\prime}$ was obtained through a fitting analysis:

$$
M_{f}=k_{3} B / a \cdot \Delta H / H^{\prime}+c_{3}
$$


where $k_{3}$ and $c_{3}$ are the coefficient and constant terms, respectively, of the independent variable $B \Delta H / a H^{\prime}$.

\subsection{Froude Number}

Figure 8 shows the relationship between the hydrodynamic moment $M_{f}$ and $\mathrm{Fr}^{2}$. The $M_{f}$ value of the floating structure increases with increasing $\mathrm{Fr}^{2}$. Moreover, with increasing $B / a$, the growth rate of $M_{f}$ tends to increase. With increasing velocity, the recirculation zone in the downstream area increases, thereby increasing the velocity difference between the upstream and downstream faces of the structure. The kinetic energy of the flow is converted into potential energy due to the water acting on the upstream face, and the dynamic pressure increases, thereby increasing the pressure difference between the front and back surfaces of the structure, which increases the hydrodynamic moment and decreases its stability.

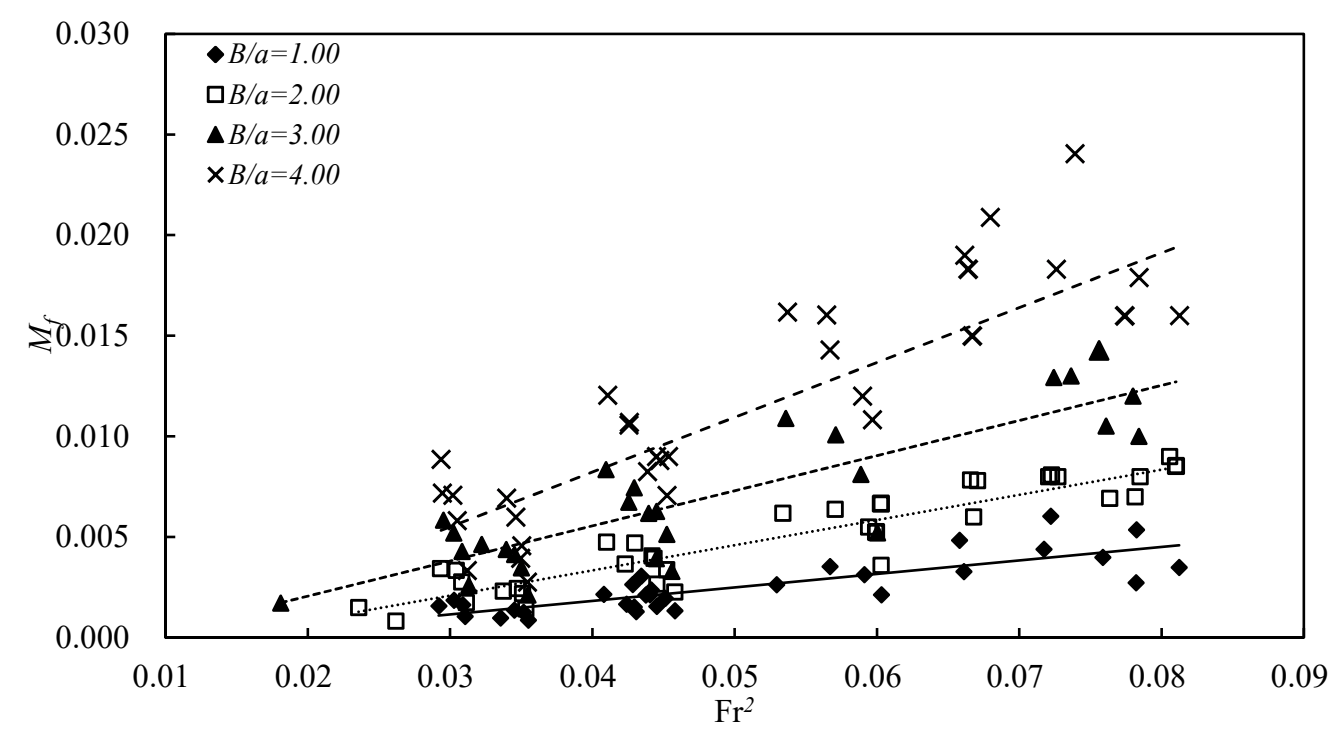

Figure 8. Relationship between $M_{f}$ and $\mathrm{Fr}^{2}$.

If we consider the effect of the Froude number and shape parameter variables as a new independent variable $B \mathrm{Fr}^{2} / a$ on $M_{f}$, the following formula can be obtained:

$$
M_{f}=k_{4} B \mathrm{Fr}^{2} / a+c_{4}
$$

where $k_{4}$ and $c_{4}$ are the coefficient and constant terms, respectively, of the independent variable $B \mathrm{Fr}^{2} / a$.

An analysis of the influencing factors in combination with the hydrodynamic moment of the floating structure in a submerged state reveals both similarities and differences in the hydrodynamic moments of the floating structure in the two different states. In both states, as the shape parameter of the structure and the water level difference increase, the hydrodynamic moment of the floating structure shows an increasing trend. However, the variation trends of $\mathrm{Fr}$ and the position (draft depth) in these two states are not the same: in a submerged state, the surface of the structure is affected by the pressure of the flowing water, while in a floating state, the upper surface of the floating body is at atmospheric pressure. Hence, the area over which kinetic energy acts on the surface of the floating structure differs between the two states, resulting in a change in the pressure difference. 


\section{Stepwise Regression Analyses and Validation of $M_{f}$}

\subsection{Regression Analysis of $M_{f}$}

Fitting the relevant factors of the scatter plots indicates that four dimensionless parameterindependent variables affect the hydrodynamic moment: $B h / a H^{\prime}, B \mathrm{Fr}^{2} / a, B \Delta H / a H^{\prime}$ and $B \ln (h / \Delta H) / a$. Based on the least squares method, stepwise regression analysis was performed to optimize and eliminate the relevant independent variables. The confidence intervals of the introduced and excluded variables are $95 \%$ and $90 \%$, respectively. The optimal mathematical expression of $M_{f}$ was obtained by excluding the repetitive variable $B \Delta H / a H^{\prime}$. The results of significance analysis of the regression equation coefficients are shown in Table 2.

Table 2. Significance analysis of the coefficients.

\begin{tabular}{|c|c|c|c|c|c|c|c|c|}
\hline \multirow{2}{*}{$\begin{array}{l}\text { Independent } \\
\text { Variable }\end{array}$} & \multicolumn{2}{|c|}{$\begin{array}{l}\text { Nonstandardized } \\
\text { Coefficients }\end{array}$} & \multirow[t]{2}{*}{$T$} & \multirow[t]{2}{*}{ Sig. } & \multicolumn{2}{|c|}{$\begin{array}{c}\text { Coefficient } 95 \% \\
\text { Confidence Interval }\end{array}$} & \multicolumn{2}{|c|}{ Collinear Statistics } \\
\hline & Coefficient & Standard Error & & & Lower Limit & Upper Limit & Tolerance & $V I F$ \\
\hline Constant & -0.001 & 0.000 & -1.73 & 0.08 & -0.001 & 0.000 & & \\
\hline$B \Delta H / a H^{\prime}$ & 0.045 & 0.002 & 19.99 & 0.00 & 0.040 & 0.049 & 0.66 & 1.51 \\
\hline$B \mathrm{Fr}^{2} / a$ & 0.036 & 0.002 & 15.73 & 0.00 & 0.031 & 0.040 & 0.51 & 1.97 \\
\hline$\Delta h$ & -0.001 & 0.000 & -2.21 & 0.00 & 0.000 & 0.000 & 0.73 & 1.38 \\
\hline
\end{tabular}

According to the significance of the coefficients and a collinear analysis, the formula for calculating the dimensionless $M_{f}$ of a floating structure of unit length is as follows:

$$
M_{f}=-0.001+\frac{B}{a}\left[0.045 \frac{\Delta H}{H^{\prime}}+0.036 \mathrm{Fr}^{2}-0.001 \ln \left(\frac{h}{\Delta H}\right)\right]
$$

where $B$ is the width of the floating structure $[\mathrm{m}] ; h$ is the draft depth $[\mathrm{m}] ; a$ is the height of the floating structure $[\mathrm{m}] ; H^{\prime}$ is the depth of the downstream water [m]; $\Delta H$ is the upstream and downstream water level difference $[\mathrm{m}]$, and $\mathrm{Fr}$ is the Froude number. The moment center of the formula is the geometric center of the floating structure. This formula is applicable under conditions of $1 \leq B / a \leq 4, a>h>0,0<\Delta H / H^{\prime} \leq 0.10$, and $\mathrm{Fr} \leq 0.35$.

The above formula reflects the hydrodynamic moment of a floating structure from entering to becoming fully immersed in the water. When the floating structure is used as a sluice in a water conservancy project, it sinks to the sluice floor to connect with the river channel. The factors involved in this formula are the shape parameter and position of the structure and the hydraulic conditions around the floating structure. Therefore, the topographic features of the upstream and downstream parts of the channel have little influence on the hydrodynamic moment, and thus, the above formula can be applied to complex irregular channels and complex bedforms.

\subsection{Verification and Error Analysis}

To evaluate the accuracy of Equation (9), the adjusted multiple correlation coefficient (AMCC) and standard error of estimation (SEE) were used. The AMCC is a modified version of the multiple correlation coefficient; it gives the percentage of variation explained by only those significant variables that affect the predicted value in reality. The AMCC value indicates the goodness of the fit of $M_{f}$; thus, the AMCC was used to verify the correctness of the prediction and to ascertain whether the regression model is satisfactory. The SEE value evaluates the reliability of the data, with smaller values indicating higher reliability, which indicates that the observations are closer to the fitted line. The AMCC and SEE are defined as follows:

$$
R^{2}=\frac{\sum_{k=1}^{K}\left(\widetilde{y_{k}}-\bar{y}\right)^{2}}{\sum_{k=1}^{K}\left(y_{k}-\bar{y}\right)^{2}}
$$




$$
\begin{gathered}
\mathrm{AMCC}=R^{2}-\frac{J \times\left(1-R^{2}\right)}{K-J-1} \\
\mathrm{SEE}=\sqrt{\frac{\sum_{k=1}^{K}\left(y_{k}-\widetilde{y_{k}}\right)^{2}}{K-J-1}}
\end{gathered}
$$

where $R^{2}$ is the coefficient of determination, $K$ is the size of the dataset, $J$ is the number of dimensionless independent variables, and $y_{k}$ is the measured value of $M_{f}$. Here, $\widetilde{y_{k}}$ is the value of $M_{f}$ estimated by Equation (9), and $\bar{y}$ is the mean value of $y_{k}$.

The AMCC and SEE values determined for Equation (9) are 0.94 and 0.01, respectively, thus proving that the significance is strong.

The model was further tested to judge the applicability of the regression equation and the fitting effect. A 95\% confidence interval was selected; the corresponding value of $F$ is 454.51. In addition, the autocorrelation of the model, which reflects the ability to conduct valid statistical tests, was evaluated by using the commonly used Durbin-Watson $(D W)$ test. The value of $D W$ was calculated as 2.39, indicating that no autocorrelation exists in the model. The correlation coefficient of the formula between the variables is low, suggesting that the independent variables are not correlated. To eliminate the instability of the model, the variance inflation factor (VIF) was used to diagnose the existence of multicollinearity. The maximum VIF value was 1.97; thus, there is no multicollinearity problem between the variables and $M_{f}$. The $F$-test, $D W$ test and VIF test formulas are given as follows:

$$
\begin{gathered}
F=\frac{\sum_{k=1}^{K}\left(\widetilde{y_{k}}-\overline{y_{k}}\right)^{2} / K}{\sum_{k=1}^{K}\left(y_{k}-\widetilde{y_{k}}\right)^{2} /(K-J-1)} \\
D W=\frac{\sum_{t=1}^{K}\left(e_{t}-e_{t-1}\right)}{\sum_{t=2}^{K} e_{t}^{2}} \\
V I F_{i}=\left(1-R_{i}^{2}\right)^{-1}
\end{gathered}
$$

where $\overline{y_{k}}$ is the mean value of $\widetilde{y_{k}}, e_{t}$ is the error term at time $t$, and $R_{i}^{2}$ is the multiple coefficient of determination of the independent variable.

The standard residuals need to satisfy the requirements of randomness and normality to confirm the correctness of the obtained formula. The following results were obtained by analyzing the standard residuals. Figure 9 illustrates the corresponding statistical analysis of the residuals of Equation (9) and a histogram of the residuals with a normal probability curve; the residuals present a normal distribution. The $95 \%$ distribution of standardized residuals is between -2 and +2 , which suggests that the model assumptions are reasonable.

For $M_{f}$, a comparison between the measured and calculated results is shown in Figure 10, suggesting good agreement. Thus, the development of a calculation formula for the overturning moment was deemed successful. 


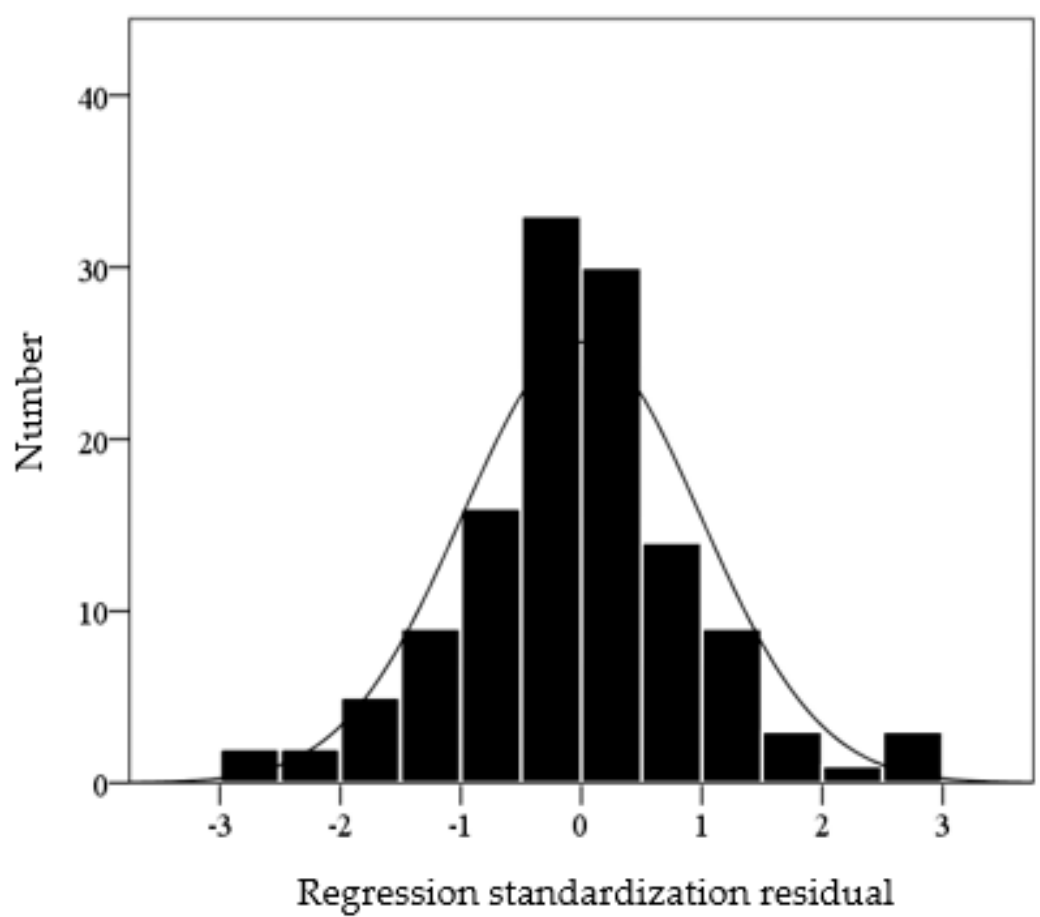

Figure 9. Residual distribution histogram.

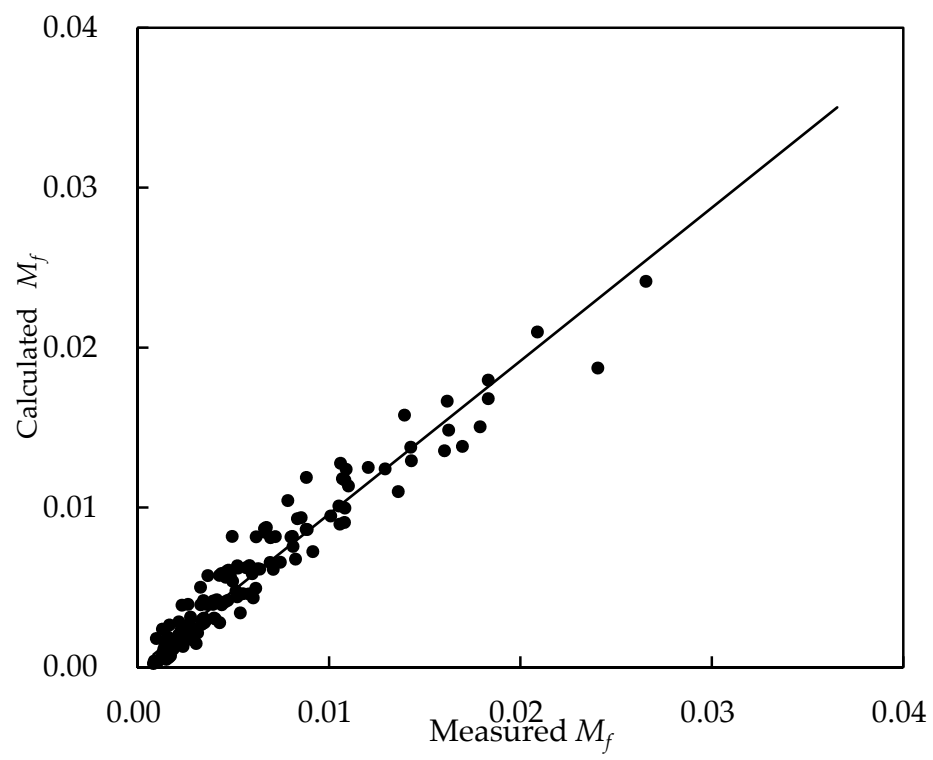

Figure 10. Comparison between the measured and calculated values of $M_{f}$.

\section{Conclusions}

Using a physical model test and theoretical analysis, the factors affecting the hydrodynamic moment $M_{f}$ of a floating structure were obtained based on dimensional analysis. The characteristics of the moment and the correlations between the influencing factors and the moment were analyzed, and an expression of the moment was derived. The main conclusions are as follows.

The hydrodynamic moment increases with increases in the shape parameter, relative draft depth, relative water level difference and Froude number of a floating structure. The surface pressure difference of a larger structure caused by the uneven distribution of the dynamic pressure and the distance between the action point and the center of the floating structure also increases, thereby increasing the hydrodynamic moment. When the relative 
water level difference rises, the pressure difference between the front and back surfaces of the structure increases, and the kinetic energy acting on the upstream surface leads to a dynamic pressure increase with a larger Froude number, raising the hydrodynamic moment. Moreover, there are positive linear correlations between the hydrodynamic moment and the shape parameter, relative water level difference and Froude number; however, the relationship between the moment and the ratio of the draft depth to the water level difference is logarithmic.

Based on the results of multivariate linear least squares fitting, stepwise regression analysis was performed to quantitatively obtain a mathematical expression describing the hydrodynamic moment of the floating structure $\left(1 \leq B / a \leq 4 ; a>h>0 ; 0<\Delta H / H^{\prime} \leq 0.10\right.$ and $\mathrm{Fr} \leq 0.35)$. Statistical indices were used to quantitatively investigate the accuracy of the formula; the AMCC and SEE values were 0.94 and 0.01 , respectively, and the residuals of the formula presented a normal distribution. The obtained formula is easy to calculate and coincides with experimentally measured values and can therefore provide guidance for calculating the hydrodynamic moment of a floating structure.

Author Contributions: Z.C. performed the experiments, analyzed the data and wrote the paper. Y.-J.C. and S.-Y.P. performed the experiments and improved the quality of the paper. The authors also thank the reviewers for their valuable comments, which significantly improved the quality of the paper. All authors have read and agreed to the published version of the manuscript.

Funding: This research was funded by the Changzhou Institute of Technology High-level Talent Research Start-up Funds, grant number (YN 20068).

Institutional Review Board Statement: Not applicable.

Informed Consent Statement: Not applicable.

Data Availability Statement: Not applicable.

Conflicts of Interest: The authors declare no conflict of interest.

\section{Notations}

The following symbols are used in this paper:

$\begin{array}{ll}a & \text { Height of the structure } \\ B & \text { Width of the structure } \\ \mathrm{Fr}^{2} & \text { Froude number: } \mathrm{Fr}^{2}=v^{2} / g H \\ g & \text { Gravitational constant of acceleration } \\ H & \text { Upstream water depth } \\ H^{\prime} & \text { Downstream water depth } \\ h & \text { Draft of the structure } \\ L & \text { Length of the structure } \\ q & \text { Discharge per width of flow } \\ R^{2} & \text { Coefficient of determination } \\ v & \text { Average flow velocity } \\ \Delta H & \text { Water level difference } \\ \rho & \text { Water density } \\ \text { AMCC } & \text { Adjusted multiple correlation coefficient } \\ \text { SEE } & \text { Standard error of estimation }\end{array}$

\section{References}

1. Zhang, Q.; Xie, L.H.; Zhou, J. Design of floating gate for overhaul of navigable drainage sluice in the old port of Jin-qing. Water Resour. Plan. Des. 2013, 6, 80-82.

2. Olyaie, E.; Banejad, H.; Chau, K.; Melesse, A.M. A comparison of various artificial intelligence approaches performance for estimating suspended sediment load of river systems: A case study in United States. Environ. Monit. Assess. 2015, 187, 189. [CrossRef]

3. Pu, J.H.; Pandey, M.; Hanmaiahgari, P.R. Analytical modelling of sidewall turbulence effect on streamwise velocity profile using 2D approach: A comparison of rectangular and trapezoidal open channel flows. J. Hydro-Environ. Res. 2020, 32, 17-25. [CrossRef] 
4. $\mathrm{Pu}, \mathrm{J} . \mathrm{H}$. Turbulent rectangular compound open channel flow study using multi-zonal approach. Environ. Fluid Mech. 2018, 19, 785-800. [CrossRef]

5. Lee, S.; Hong, C. Characteristics of wave exciting forces on a very large floating structure with submerged-plate. J. Mech. Sci. Technol. 2005, 11, 2061-2067. [CrossRef]

6. Venugopal, V.; Varyani, K.S.; Barltrop, N.D.P. Wave force coefficients for horizontally submerged rectangular cylinders. Ocean Eng. 2006, 33, 1669-1704. [CrossRef]

7. Roy, P.D.; Ghosh, S. Wave force on vertically submerged circular thin plate in shallow water. Ocean Eng. 2006, 33, 1935-1953. [CrossRef]

8. Hayatdavoodi, M.; Seiffert, B.; Ertekin, R.C. Experiments and computations of solitary-wave forces on a coastal-bridge deck. Part II: Deck with girders. Coast. Eng. 2014, 88, 210-228. [CrossRef]

9. Seiffert, B.; Hayatdavoodi, M.; Ertekin, R.C. Experiments and computations of solitary-wave forces on a coastal-bridge deck. Part I: Flat plate. Coast. Eng. 2014, 88, 194-209. [CrossRef]

10. Xing, D.L. Research on hydrodynamic performance of floating bodies in confined zone. J. Dalian Univ. Technol. 1993, 3, 351-355.

11. Xing, D.L.; Deng, Y.P.; Zhou, M. Experimental research for added mass of cylinders with reflected boundary condition. J. Dalian Univ. Technol. 1998, 4, 107-111.

12. Wang, S.; Fu, Z.F.; Cui, Z.; Chen, Y.J. Analysis of the influencing factors of overturning moment on the floating structure surrounded with flowing water. J. Hohai Univ. 2018, 46, 66-71. [CrossRef]

13. Cui, Z.; Wang, S.; Fu, Z.F. Influence of mesh scale on hydrodynamic characteristics of floating body. Water Resour. Power 2016, 12, 101-105.

14. Fu, Z.F.; Yin, X.; Gu, X.F. Hydraulic characteristics of floating sluices subsiding and buoying in flowing water. Adv. Water Resour. 2014, 5, 24-27. [CrossRef]

15. Lu, X.; Wang, K. Modeling a solitary wave interaction with a fixed floating body using an integrated analytical-numerical approach. Ocean Eng. 2015, 109, 691-704. [CrossRef]

16. Rodrigues, J.M.; Guedes, S.C. A generalized adaptive mesh pressure integration technique applied to progressive flooding of floating bodies in still water. Ocean Eng. 2015, 110, 140-151. [CrossRef]

17. Cui, Z.; Fu, Z.F.; Chen, Y.J. Explore the flow characteristics of floating structure based on the orthogonal design method. Eng. J. Wuhan Univ. 2018, 6, 471-477. [CrossRef]

18. Cui, Z.; Fu, Z.F.; Wang, J. Sensitivity analysis of influencing factors of hydraulic characteristics of floating structure in finite flowing water. Eng. J. Wuhan Univ. 2018, 11, 957-962. [CrossRef]

19. Fu, Z.F.; Yan, Z.M. Stability analysis of a new floating body brake. J. Hydraulics. Eng. 2005, 8, 1014-1018. [CrossRef]

20. Venugopal, V.; Varyani, K.S.; Westlake, P.C. Drag and inertia coefficients for horizontally submerged rectangular cylinders in waves and currents. Proc. Inst. Mech. Eng. Part J-J. Eng. Tribol. 2009, 223, 121-136. [CrossRef]

21. Rey, V.; Touboul, J.; Sous, D. Effect of a Submerged Plate on the Near-bed Dynamics under Incoming Waves in Deep Water Conditions. Appl. Ocean Res. 2015, 53, 67-74. [CrossRef]

22. Johnson, H.K.; Karambas, T.V.; Avgeris, I. Modeling of Waves and Currents around Submerged Breakwaters. Coast. Eng. 2005, 52, 949-969. [CrossRef]

23. Wan, Z.N.; Zhai, G.G.; Cheng, Y. Prediction on hydro-elastic responses of very large floating structure on the sea. J. Harbin. Eng. Univ. 2014, 10, 1189-1194. [CrossRef]

24. Zhang, L.P. Study on Hydraulic Characteristics of Floating Sluice Localization Process; Hohai University: Nanjing, China, 2007.

25. Rey, V.; Touboul, J. Forces and moment on a horizontal plate due to regular and irregular waves in the presence of current. Appl. Ocean Res. 2011, 33, 88-99. [CrossRef]

26. $\mathrm{Pu}, \mathrm{J} . \mathrm{H}$. Velocity profile and turbulence structure measurement corrections for sediment transport-induced water-worked bed. Fluids 2021, 6, 86. [CrossRef]

27. Pu, J.H.; Wei, J.; Huang, Y.F. Velocity distribution and 3D turbulence characteristic analysis for flow over water-worked rough bed. Water 2017, 9, 668. [CrossRef]

28. Li, Y.; Lin, M. Hydrodynamic coefficients induced by waves and currents for submerged circular cylinder. Procedia Eng. 2010, 4, 253-261. [CrossRef]

29. Cui, Z.; Fu, Z.F.; Dai, W.H.; Lai, Z.Q. Submerged fixed floating structure under the action of surface current. Water 2018, 10, 102. [CrossRef]

30. Goring, D.G.; Nikora, V.I. Despiking acoustic doppler velocimeter data. J. Hydraul. Eng. 2002, 128, 117-126. [CrossRef]

31. Blanckaert, K.; Lemmin, U. Means of noise reduction in acoustic turbulence measurements. J. Hydraul. Res. 2006, 44, 1-15. [CrossRef] 